\title{
Transient Reciprocal Change of Renal Hepatocyte Growth Factor and Transforming Growth Factor- $\beta 1$ May Relate to Renal Hypertrophy in Rats with Liver Injury or Unilateral Nephrectomy
}

\author{
YONG-KWEI TSAU, I-JUNG TSAI, AND YUNG-MING CHEN
}

\author{
Department of Pediatrics [Y.-K.T., I.-J.T.], Department of Medicine [Y.-M.C.], National Taiwan University Hospital, Taipei 100, Taiwan
}

\begin{abstract}
We examined an animal model of liver injury using ligation of the common bile duct (CBD) in young rats to observe nephromegaly and to determine plasma and renal changes in hepatocyte growth factor (HGF) and transforming growth factor (TGF)$\beta 1$. To examine the role of TGF- $\beta 1$ in the process of compensatory renal growth, renal tissue HGF, TGF- $\beta 1$, TGF- $\beta 1$ mRNA, and c-met protein were measured. Plasma HGF level decreased significantly at $1 \mathrm{wk}$, and plasma TGF- $\beta 1$ level also decreased at $1 \mathrm{wk}$ and remained low at 2 wk after surgery in CBD ligation rats. Increased renal HGF/TGF- $\beta 1$ ratio was noted at $2 \mathrm{wk}$, followed by a higher kidney weight/body weight ratio and an elevated protein/DNA ratio at 3 wk after operation in CBD ligation rats. The increased renal HGF/TGF- $\beta 1$ ratio in CBD ligation rats was mainly attributed to elevated renal HGF levels. Renal HGF/TGF- $\beta 1$ ratio was also elevated at $12 \mathrm{~h}$ after unilateral nephrectomy. This elevated renal HGF/TGF- $\beta 1$ resulted exclusively from low renal TGF- $\beta 1$. Renal TGF- $\beta 1$ mRNA decreased significantly at $12-24 \mathrm{~h}$ after surgery in unilateral nephrectomized rats, whereas renal c-met receptor protein levels increased. Transient reciprocal change of HGF and TGF- $\beta 1$ manifesting as an increased renal HGF/TGF- $\beta 1$ ratio soon after uninephrectomy and later during CBD ligation suggests the probable role of TGF- $\beta 1$ in renal growth control and its possible initiating of renal hypertrophy in liver injury or unilateral nephrectomy. (Pediatr Res 59: 494-499, 2006)
\end{abstract}

$\mathrm{N}^{\mathrm{e}}$ ephromegaly is a rarely mentioned but likely common situation in children with biliary atresia (1). We previously postulated the possible role of HGF in such a situation (2). HGF is a potent mitogen for hepatocytes after liver injury (3) and may act as a renotropic factor in compensatory renal growth and renal regeneration (4-7). TGF- $\beta 1$ is an antiproliferative cytokine (8) that may act as an inhibitor of renal cell growth. Our later work, which revealed a positive correlation between plasma HGF/TGF- $\beta 1$ ratio and nephromegaly in children with biliary atresia or severe hepatitis (9), further suggested the possible pathogenic role of HGF and its manifesting as elevated $\mathrm{HGF} / \mathrm{TGF}-\beta 1$ ratios in patients with

Received April 13, 2005; accepted November 9, 2005.

Correspondence: Yong-Kwei Tsau, M.D., Department of Pediatrics, National Taiwan University Hospital, No. 7 Chung-Shan South Road, Taipei 100, Taiwan; e-mail: tsau07@ha.mc.ntu.edu.tw

This work was supported by grants from the National Science Council of Taiwan (NSC90-2314-B002-162 and NSC91-2314-B002-214).

DOI: 10.1203/01.pdr.0000203101.18174.fe such conditions. The reciprocal change of plasma HGF and TGF- $\beta 1$ in these children may reduce the antiproliferative effect of TGF- $\beta 1$ and potentiate the proliferative action of HGF, resulting in nephromegaly. Children with biliary atresia had an elevated renal mass nearly twice the normal total kidney volume, and correlated with elevated plasma HGF level and HGF/TGF- $\beta 1$ ratio (10). Children with compensatory renal hypertrophy, however, had compensatory increase in total renal volume up to that seen in healthy children. They initially had elevated plasma HGF but later had normal plasma HGF and HGF/TGF- $\beta 1$ (10). These data suggest a common mechanism of initial renal hypertrophy with dysregulation of control of the process later in biliary atresia. TGF- $\beta 1$ may be a logical candidate to terminate further compensatory hypertrophy by HGF. Thus the low plasma TGF- $\beta 1$ in biliary atresia may play a role in the dysregulation of HGF. In other words, if it is true that elevated HGF/TGF- $\beta 1$ ratio is associated with or responsible for nephromegaly, the reciprocal change between HGF and TGF- $\beta 1$ may be transient in compensatory renal hypertrophy and should be persistent in biliary atresia.

In 1957, Trams and Symeonidis (11) observed the presence of enlarged kidneys in their study on liver damage of rats after ligation of the common bile duct. Unfortunately, no detailed description or further information about this observation has been followed in the literature. We thus created the same animal model of liver injury using ligation of the common bile duct in rats to observe the nephromegaly, determine the nature of nephromegaly, and examine the plasma and renal changes of HGF and TGF- $\beta 1$ in this situation. HGF is a potent renotropic factor that may be involved very early in postnephrectomy renal hypertrophy (5-7). To examine the role of TGF- $\beta 1$ in the process of postnephrectomy renal growth, we also investigated the possible reciprocal change of renal HGF and TGF- $\beta 1$ in unilateral nephrectomized rats.

Abbreviations: CBD, common bile duct; HGF, hepatocyte growth factor; TGF- $\boldsymbol{\beta} 1$, transforming growth factor- $\beta 1$ 


\section{MATERIALS AND METHODS}

Experimental animals. Male Wistar rats ( $25 \mathrm{~d}$ old) were used for CBD ligation and unilateral nephrectomy. Operations were performed using pentobarbital $(50 \mathrm{mg} / \mathrm{kg}$ i.p. $)$ anesthesia. The rats were kept in cages and fed standard chow and water ad libitum. All experimental protocols were approved by the Animal Committee of National Taiwan University.

Animal models of nephromegaly in liver injury. Experimental obstruction of CBD was obtained by isolating the CBD with double ligation and division via ventral laparotomy $(4,10)$. The control group of rats underwent sham operation, in which laparotomy was performed and the CBD was dissected but not ligated. Six to 12 rats from each group were killed 1, 2, and 3 wk after surgery. Since just half the rats with CBD ligation survived for $3 \mathrm{wk}$ following the operation, the experimental group killed at $3 \mathrm{wk}$ included only four rats. Blood was collected and both kidneys excised after saline perfusion in situ to remove blood during sacrifice. Body weight and total kidney weight were measured in each rat. The kidneys were immediately frozen in liquid nitrogen and stored at $-70^{\circ} \mathrm{C}$ for subsequent DNA extraction and tissue lysate preparation.

Animal models of postnephrectomy compensatory renal growth. For uninephrectomy, the right kidney was excised immediately through a midline incision after anesthesia, the abdomen was closed, and the rat was allowed to recover for various time periods before removal of the remaining kidney. For sham operation, animals were anesthetized and the abdomen was surgically opened, followed by blunt dissection of the renal fascia. The abdomen was then closed, and the animals were allowed to recover for a time until sacrifice. Six rats from each group were killed $6,12,24,48$, and $72 \mathrm{~h}$, and $7 \mathrm{~d}$ after surgery. Blood was collected and the kidneys removed, weighed, and snapfrozen in liquid nitrogen after saline perfusion during sacrifice.

Isolation of RNA, DNA, and proteins. The simultaneous isolation of total RNA, DNA, and proteins was prepared by a single-step method using TRI Reagent (12) according to the instructions specified by the manufacturer (Molecular Research Center Inc., Cincinnati, OH). Briefly, the rat kidney was homogenized in TRI Reagent $(0.1 \mathrm{~g}$ tissue $/ \mathrm{mL})$ and the homogenate was separated into aqueous and organic phases by chloroform addition and centrifugation. RNA remained exclusively in the aqueous phase, DNA in the interphase, and proteins in the organic phase. RNA was precipitated from the aqueous phase by addition of isopropanol, washed with ethanol, and solubilized. DNA and proteins were sequentially precipitated from the interphase and the organic phase with ethanol and isopropanol, washed with ethanol, and solubilized. RNA was quantitated by spectrophotometry at $260 \mathrm{~nm}$ and 280 $\mathrm{nm}$. Total RNA with $\mathrm{OD}_{260} / \mathrm{OD}_{280}$ ratios over 1.8 and intact ribosomal RNA bands on ethidium bromide-stained agarose gels was used for Northern blot analysis. Concentration and purity of DNA were analyzed by a U-2000 spectrophotometer (Hitachi, Tokyo, Japan). The protein concentration was determined using a protein assay kit (Sigma Chemical Co., St. Louis, MO).

ELISA for HPC and TGF- $\boldsymbol{\beta} 1$. Renal tissue and plasma HGF levels were measured using a commercial ELISA kit (Institute of Immunology, Tokyo, Japan). The ELISA kit uses a sandwich method consisting of three steps of antigen-antibody reactions. Briefly, a mouse antirat HGF MAb was coated onto 96-well microtiter plates. Fifty-microliter aliquots of standard rat HGF solution or samples were added to the wells and were incubated for $18 \mathrm{~h}$ at room temperature. After extensive washing, a 100- $\mu \mathrm{L}$ aliquot of rabbit antirat HGF polyclonal antibody was added and the plates incubated for another $2 \mathrm{~h}$. They were then incubated with peroxidase-labeled goat antirabbit IgG for an additional $2 \mathrm{~h}$, followed by incubation with enzyme substrate solution. The plates were allowed to stand for $30 \mathrm{~min}$ at room temperature, and the reaction was stopped by the addition of $50 \mu \mathrm{L} 4 \mathrm{~N} \mathrm{H}_{2} \mathrm{SO}_{4}$. Absorbance was read at 490 $\mathrm{nm}$ by an Anthos 2010 automatic microplate reader (Anthos Labtec Instruments GmbH, Salzburg, Austria).

Renal and plasma TGF- $\beta 1$ levels were measured using a human TGF- $\beta 1$ kit (R\&D Systems, Minneapolis, MN). After activating the procedure for samples with $2.5 \mathrm{~N}$ of acetic acid/10M of urea and $2.7 \mathrm{~N}$ of $\mathrm{NaOH} / 1 \mathrm{M}$ of HEPES, $200 \mu \mathrm{L}$ of activated samples were added to each well precoated with type- 2 TGF- $\beta$ soluble receptor. After mixing and incubation for $3 \mathrm{~h}$ at room temperature, each well was washed four times with buffered surfactant. TGF- $\beta 1$ conjugate $(200 \mu \mathrm{L})$ was then added to each well and incubated for $1.5 \mathrm{~h}$ at room temperature. Finally, $200 \mu \mathrm{L}$ of substrate solution was added, followed by $50 \mu \mathrm{L}$ of stop solution, and $\mathrm{OD}$ was determined using a spectrophotometer set to $450 \mathrm{~nm}$.

The protein concentration of renal samples was determined simultaneously using a protein assay kit (Sigma Chemical Co.). The concentrations of HGF and TGF- $\beta 1$ in tissues were expressed as nanograms per milligram protein or per gram tissue.

Western blot analysis for renal c-met protein determination. After determination of protein concentration, renal tissue lysates were mixed with an equal amount $2 \times$ loading buffer [0.1M Tris-HCl, $4 \%$ SDS, $20 \%$ glycerol, and
$0.2 \%$ bromophenol blue]. Samples were separated on a $10 \%$ SDSpolyacrylamide gel under nonreducing conditions. The proteins were electrotransferred to a polyvinylidene difluoride membrane (Millipore, Bedford, MA) in a transfer buffer containing $0.048 \mathrm{M}$ Tris- $\mathrm{HCl}, 0.039 \mathrm{M}$ glycine, and $20 \%$ methanol at $4^{\circ} \mathrm{C}$ for $1 \mathrm{~h}$. Nonspecific binding to the membrane was blocked for $1 \mathrm{~h}$ at room temperature with 5\% Carnation nonfat milk in a TBS buffer $(0.02 \mathrm{M}$ Tris- $\mathrm{HCl}, \mathrm{pH} 7.5,0.15 \mathrm{M}$ sodium chloride, and $0.1 \%$ Tween 20). The membrane was then incubated at $4{ }^{\circ} \mathrm{C}$ for $16 \mathrm{~h}$ with an affinity-purified polyclonal rabbit $\mathrm{IgG}$ raised against the synthetic peptide corresponding to the C-terminal amino acids of mouse c-met protein (SP260; Santa Cruz Biochemicals, Santa Cruz, CA), followed by incubation for $1 \mathrm{~h}$ with a goat antirabbit IgG horseradish peroxidase conjugate (Bio-Rad, Hercules, CA) in $1 \%$ nonfat milk. Bands were visualized by the enhanced chemiluminescence (ECL) system (Amersham Life Science, Arlington Heights, IL).

Northern blot analysis for TGF-B1 mRNA expression. Northern blotting for gene expression was carried out by published procedures (13). Briefly, samples of $20 \mu \mathrm{g}$ total RNA were electrophoresed on $1 \%$ formaldehydeagarose gels in a MOPS buffer $(0.2 \mathrm{M}$ morpholinopropanesulfonic acid, $0.05 \mathrm{M}$ sodium acetate, $0.01 \mathrm{M}$ ethylenediaminetetraacetic acid). Subsequently, the RNA was transferred to nylon membranes by overnight capillary action followed by fixation in a UV cross-linker. Hybridization was then performed with digoxigenin-labeled rat TGF- $\beta 1$ RNA probes. For the synthesis of rat TGF- $\beta 1$ riboprobes, cDNA fragments were first generated by reverse transcription PCR from glomerular RNA of anti-Thy1-injected rats using the following specific primer pairs: upstream, 5'-TCCACAGAGAAGAACTGCTG-3' (corresponding to bases 1214 to 1233) and downstream, 5'ACTTGCAGGAGCGCACAATC-3' (corresponding to bases 1498 to 1517) (13). The blots were developed using CSPD (Roche Molecular Biochemicals, Mannheim, Germany) as the substrate for alkaline phosphatase. The signal intensity recorded on $\mathrm{x}$-ray film was then quantitated with computerized densitometry and normalized against the signal of glyceraldehyde-3phosphate dehydrogenase (GAPDH) messages.

Statistical analysis. The results are expressed as mean \pm SD unless otherwise stated. An unpaired two-tailed $t$ test or Mann-Whitney $U$ test was used to compare group means. Values of $p<0.05$ were considered to be statistically significant.

\section{RESULTS}

\section{Renal hypertrophy in liver injury after CBD ligation.} There was an insignificant decrease in body weight gain and total kidney weight gain at various time points in CBD ligation rats when compared with sham operation controls (Table 1). Renal enlargement was thus assessed by kidney/ body weight ratios. Normal kidney weight/body weight ratio in rats was obtained for reference from regression analysis study in 30 normal rats aged $4-9$ wk $(r=-0.997, p<0.001)$, and can be calculated according to the formula: kidney weight/body weight ratio $=-0.11 \times$ age $($ weeks $)+1.66$. Renal tissue protein/DNA ratio was examined to determine hyperplasia or hypertrophy as the nature of nephromegaly (14). As shown in Table 1, a higher kidney weight/body weight ratio and an elevated renal protein/DNA ratio were noted in CBD ligation rats only $3 \mathrm{wk}$ after the operation. These results indicate that nephromegaly in liver injury of this animal model is really present and results from renal hypertrophy.

Association of renal hypertrophy and HGF or TGF- 11 in CBD ligation rats. Plasma HGF concentration decreased significantly at $1 \mathrm{wk}(p=0.004)$, and plasma TGF- $\beta 1$ level also decreased at $1 \mathrm{wk}(p=0.01)$ and remained low at $2 \mathrm{wk}(p=$ 0.013) after surgery in CBD ligation rats (Fig. 1). However, there were no significant differences in plasma HGF/TGF- $\beta 1$ between CBD ligation rats and sham controls (Table 1). Renal HGF/TGF- $\beta 1$ started rising in several experimental rats at 1 wk $(p=0.135)$, and reached a significantly higher level $(p=$ 
Table 1. Changes in total kidney growth after ligation of CBD in 25-d-old rats

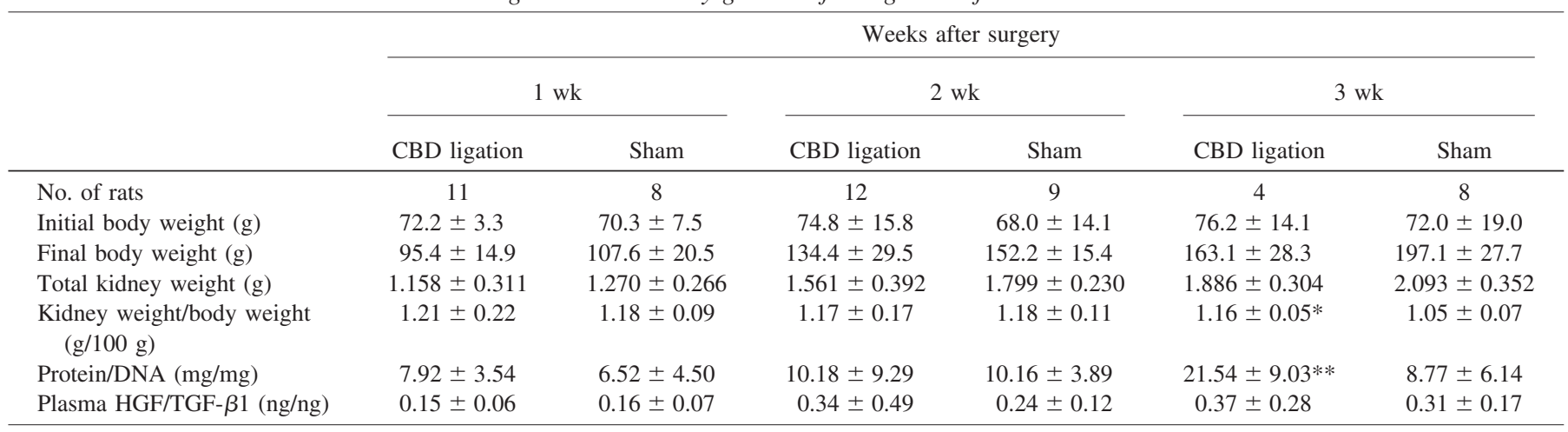

$* p=0.021, * * p=0.015$.
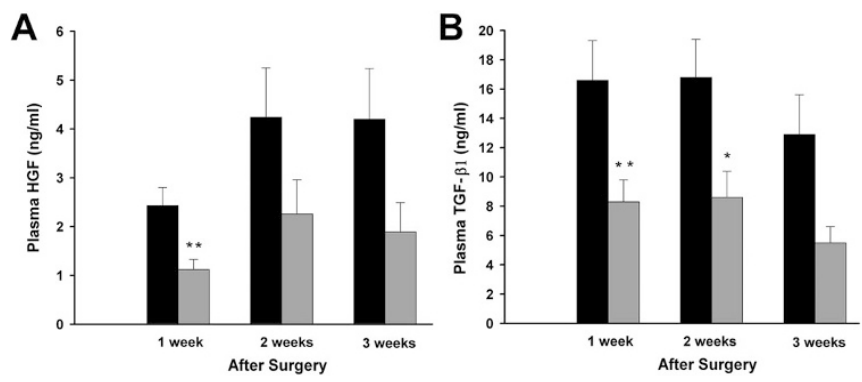

Figure 1. Plasma $\operatorname{HGF}(A)$ and TGF- $\beta 1$ (B) levels after surgery in CBD ligation $(\square)$ or sham-operated $(\square)$ rats. Data are expressed as means \pm SEM $(n=6) . * p<0.02$ and $* * p<0.01$.

0.015) than sham controls at 2 wk postoperation (Fig. 2). This elevated renal HGF/TGF- $\beta 1$ ratio may reasonably in time result in renal hypertrophy at $3 \mathrm{wk}$ after ligation of CBD. The increased HGF/TGF- $\beta 1$ ratio is mainly attributed to elevated renal tissue HGF levels (Fig. 2), but may partly result from borderline decreased renal TGF- $\beta 1(94.6 \pm 23.4 \mathrm{pg} / \mathrm{mg}$ protein in CBD ligation rats versus $125.5 \pm 49.4 \mathrm{pg} / \mathrm{mg}$ protein in sham controls, $p=0.072$ ).

Changes in renal $\mathrm{HGF} / \mathrm{TGF}-\beta 1$ ratio after unilateral nephrectomy. Table 2 shows the changes in renal growth and renal growth factors after unilateral nephrectomy. Renal HGF/ TGF- $\beta 1$ ratio was elevated $12 \mathrm{~h}$ after nephrectomy when compared with sham controls $(p=0.047)$. Single kidney weight increased $7 \mathrm{~d}$ after nephrectomy, but it did not in the first $72 \mathrm{~h}$. The elevated renal HGF/TGF- $\beta 1$ results exclusively from low renal tissue TGF- $\beta 1$ in unilateral nephrectomized rats (Fig. 3). There were no significant differences in plasma HGF or plasma TGF- $\beta 1$ between nephrectomized rats and sham controls (data not shown).

Decreased TGF-ß1 mRNA and increased c-met protein after unilateral nephrectomy. To determine whether renal TGF- $\beta 1$ mRNA was altered resulting in low renal TGF- $\beta 1$ after uninephrectomy, we examined the levels of TGF- $\beta 1$ mRNA in the kidney of sham-operated and unilateral nephrectomized rats at various times after treatments. TGF- $\beta 1$ mRNA expression decreased significantly at $12-24 \mathrm{~h}$ after unilateral nephrectomy when compared with sham controls (Fig. 4). To examine whether elevated renal HGF/TGF- $\beta 1$ up-regulated c-met receptor protein, we found that the c-met protein levels in the kidney increased significantly at $12-24 \mathrm{~h}$ after surgery in unilateral nephrectomized rats (Fig. 5).

\section{DISCUSSION}

Complete obstruction of the CBD may cause severe liver damage, resulting in poor food intake and thus poor weight gain and initial kidney growth. Liver injury may be severe enough to progress to end-stage liver disease rapidly and result in death of half the rats by three weeks after the operation (11). To examine whether nephromegaly occurred in rats with liver injury, this animal model of CBD ligation provides a rather satisfying situation that indicates real nephromegaly (about 10\% change in kidney weight/body weight ratio) in severe liver injury as observed by Trams and Symeonidis (11).
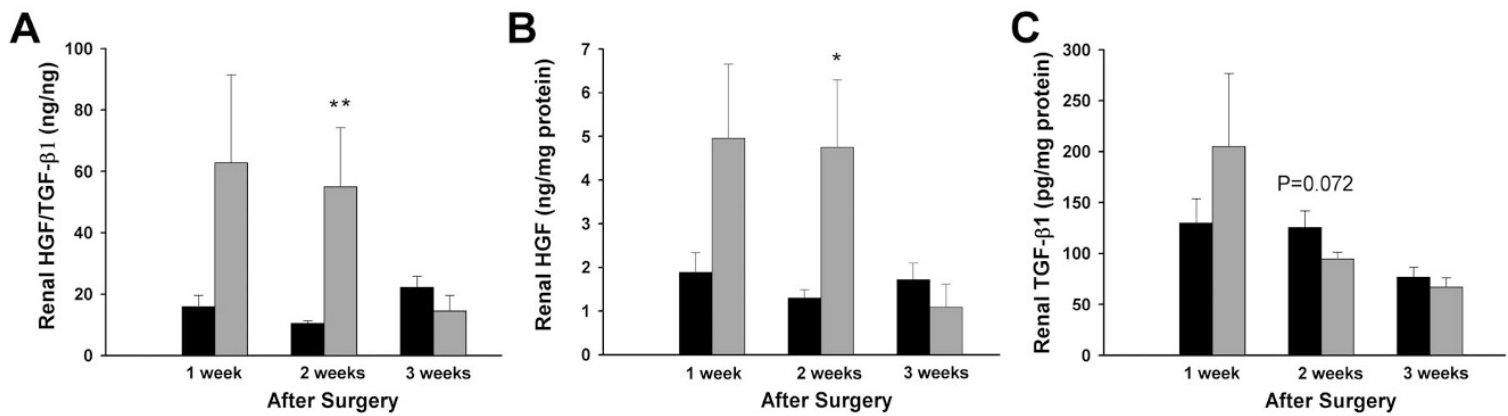

Figure 2. Renal HGF/TGF- $\beta 1(A), \operatorname{HGF}(B)$, and TGF- $\beta 1(C)$ levels after surgery in CBD ligation $(\square)$ or sham-operated ( $\square)$ rats. Data are expressed as means \pm SEM $(n=6) . * p<0.05$ and $* * p<0.02$. Although not statistically significant, $p=0.072$ for renal TGF- $\beta 1$ level between the two groups at 2 wk after treatment. 
Table 2. Changes in kidney growth and growth factors after unilateral nephrectomy in 25-d-old rats

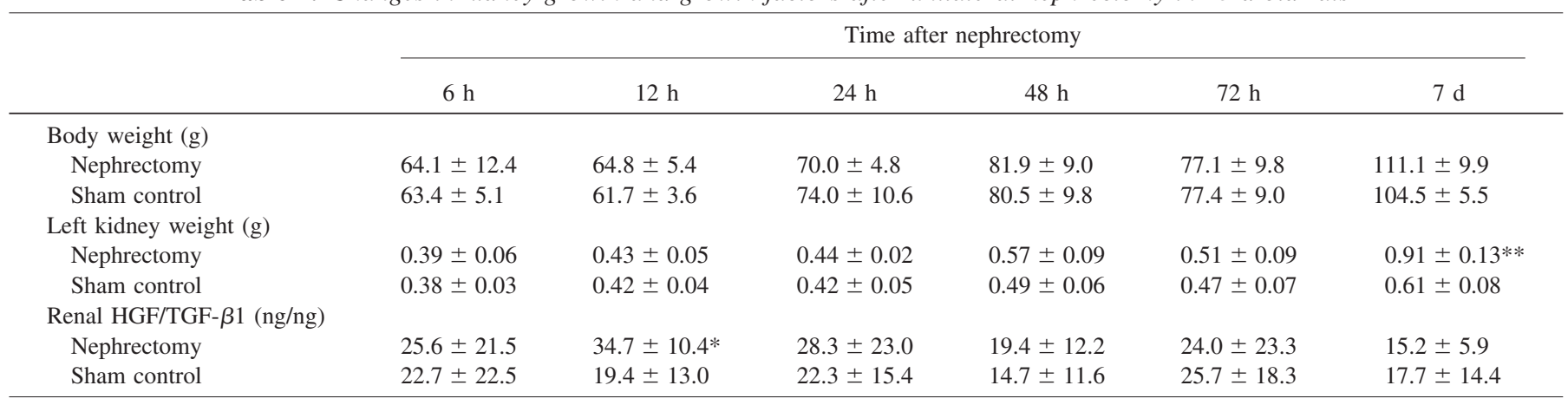

$* p=0.047, * * p<0.001$.

Data are expressed as mean $\pm \operatorname{SD}(n=6)$.

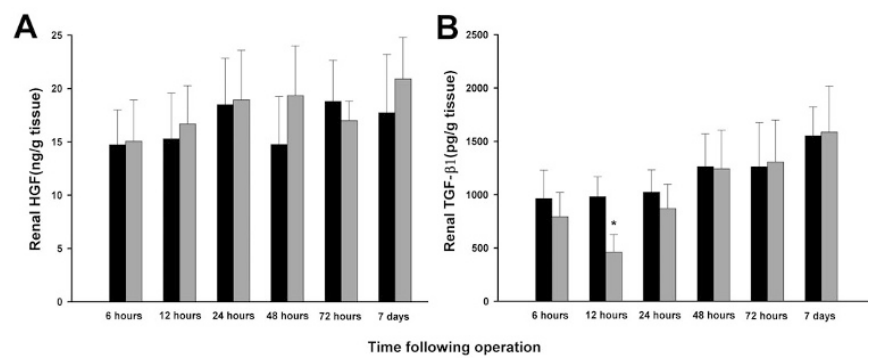

Figure 3. Renal HGF $(A)$ and TGF- $\beta 1(B)$ levels after operation in unilateral nephrectomized ( $\square, \mathrm{UN})$ or sham-operated $(\square, S C)$ rats. Data are expressed as means $\pm \operatorname{SEM}(n=6) . * p<0.05$.

To explore the mechanism of nephromegaly in severe or chronic liver injury, our data from CBD ligation rats provide evidence on the possible involvement of HGF and TGF- $\beta 1$ in this situation. Increased renal HGF/TGF- $\beta 1$ at 2 wk after CBD ligation followed by elevated kidney weight/body weight ratios and renal tissue protein/DNA ratios at $3 \mathrm{wk}$ may relate renal hypertrophy to these causative growth factors. Previously, we postulated the possible role of persistently high plasma HGF/TGF- $\beta 1$ for nephromegaly in children with biliary atresia (9). In this descriptive study, we demonstrated a transiently elevated HGF/TGF- $\beta 1$ ratio in renal tissue after liver injury and in association with the following renal hypertrophy in CBD ligation rats. This elevated renal HGF/TGF- $\beta 1$ comes mainly from increased renal HGF and possibly from decreased renal TGF- $\beta 1$. Although the reason the renal HGF/ TGF- $\beta 1$ changes in liver injury remains unknown, several reasonable explanations may be taken into consideration. Hepatic HGF mRNA increases after acute or chronic liver injury $(3,8)$ and HGF is believed to play an important role in liver regeneration and repair (8). This elevated or excess hepatic HGF may have additional endocrine effects on kidneys as we previously postulated in children with biliary atresia $(2,9)$ and result in increased renal HGF. However, instead of increased plasma HGF in biliary atresia, decreased plasma HGF in CBD ligation rats makes a hepatic origin of the increased renal HGF less likely. Interestingly, the stimulus of injury to the liver may be recognized by distal noninjured kidneys. HGF mRNA was found to increase markedly in the remnant liver as well as noninjured kidneys when the rat liver was injured by $70 \%$ partial hepatectomy (15). This finding may more exactly explain the fact of increased renal HGF in CBD ligation rats.

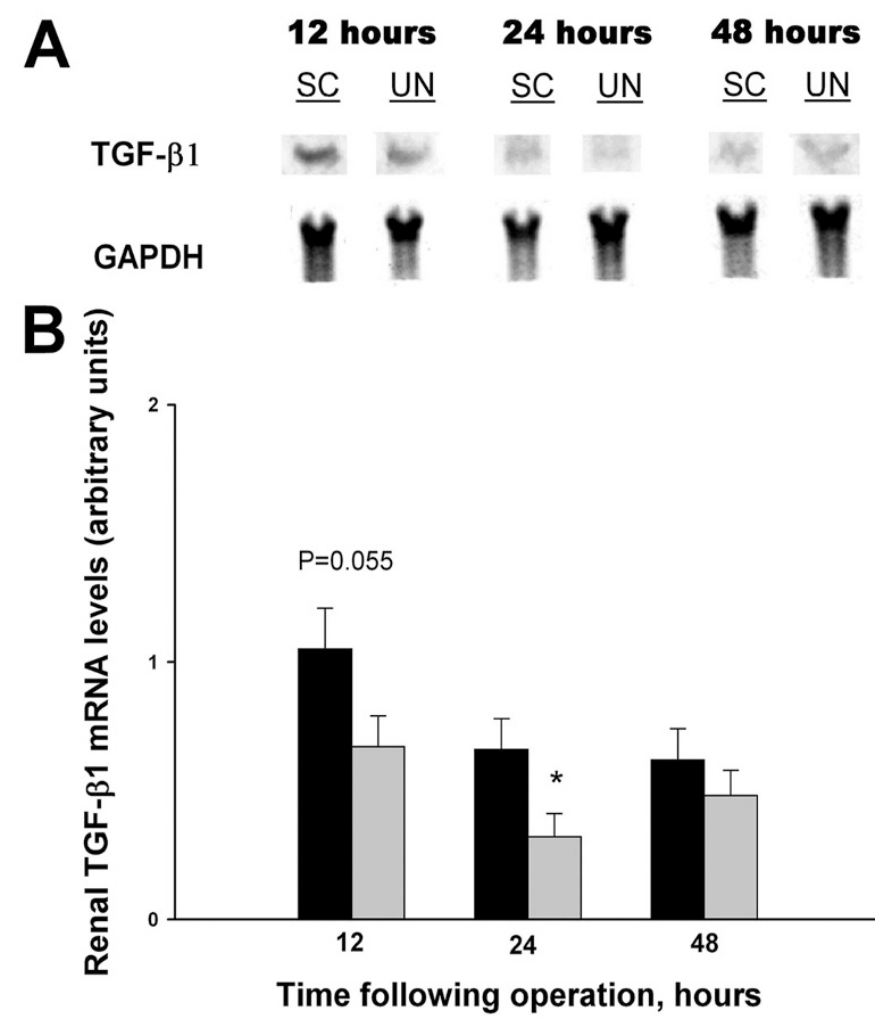

Figure 4. Northern blot analysis for TGF- $\beta 1$ mRNA expression in the whole kidney 12,24 , and $48 \mathrm{~h}$ after treatments in unilateral nephrectomized ( $\square \mathrm{UN}$ ) or sham-operated ( $\mathbf{S C}$ ) rats. (A) Representative Northern blots. Glyceraldehyde-3-phosphate dehydrogenase message is used as an internal control. (B) Quantitation of TGF- $\beta 1$ mRNA levels was plotted after analyzing hybridized signals by densitometer. Data are presented as means \pm SEM of six animals from each group and expressed as arbitrary units. ${ }^{*} p<0.05$. Although not statistically significant, $p=0.055$ between the two groups at $12 \mathrm{~h}$ after operation.

We wish to emphasize that CBD ligation and uninephrectomy techniques provide a good tool(s) to elucidate a cytokine network(s) between growth and its arrest in kidney, as investigated in liver tissues after 70\%-partial hepatectomy.

It is believed that in liver regeneration after partial hepatectomy, HGF is the initial mitogenic stimulus and TGF- $\beta 1$ stops the proliferation, leading to the termination of regeneration $(8,16,17)$. During the process of hepatocyte DNA synthesis, it is associated with gradual loss of TGF- $\beta 1$ and decreased TGF- $\beta 1$ receptors on hepatocytes (8). If renal 


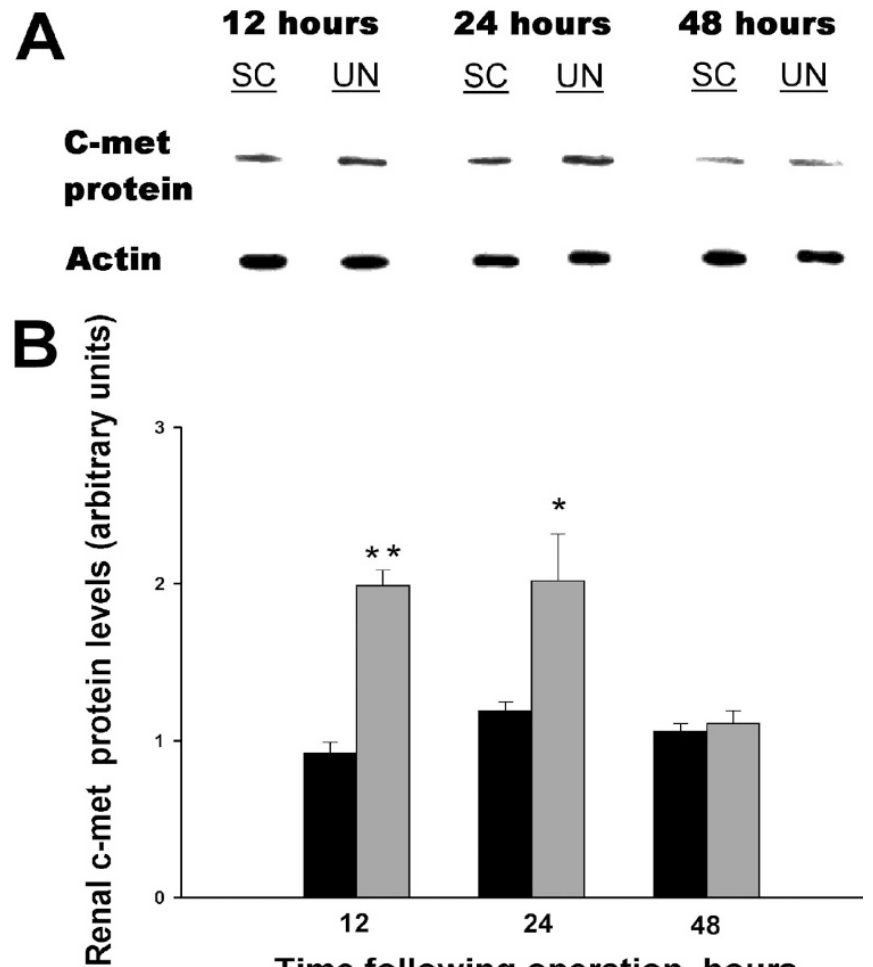

Time following operation, hours

Figure 5. Western blot analysis for c-met receptor protein in the whole kidney 12,24 , and $48 \mathrm{~h}$ after treatments in unilateral nephrectomized ( $\square \mathrm{UN}$ ) or sham-operated ( $\mathbf{S C}$ ) rats. (A) Representative Western blots. (B) Quantitation of c-met protein levels is plotted and expressed as arbitrary units. Data are presented as means \pm SEM of four animals from each group. $* p<0.05$ and ${ }^{* *} p<0.001$.

growth proceeds in a similar way, nephromegaly from this new model may depend not only on HGF, but also on TGF$\beta 1$. The low plasma TGF- $\beta 1$ and borderline decreased renal TGF- $\beta 1$ in CBD ligation rats may implicate the decreased antiproliferative effect on renal cell growth and potentiate the mitogenic action of HGF. However, how this renal HGF/ TGF- $\beta 1$ change initiates a cascaded pathway of renal hypertrophy may need further studies. The signal transduction mechanism in details or the involvement of other growth factors such as IGF-I should be clarified. The immunohistochemistry to quantify the tubular regenerative activity or hypertrophy signal may also be helpful.

TGF- $\beta 1$ modulates and inhibits HGF-mediated morphogenesis in renal tubular cells (18), whereas HGF releases TGF$\beta 1$-induced growth arrest (19). Counterbalance between HGF and TGF- $\beta 1$ has been found in the pathogenesis of chronic renal failure/renal fibrosis $(20,21)$ and probably in liver regeneration (8). Therapy with high-dose HGF can suppress the renal TGF- $\beta 1$ level, reverse the reciprocal balance between HGF and TGF- $\beta 1$, and prevent or improve chronic renal failure (22-24). It is very likely that a combination of the two growth factors participates in renal growth. Although the present CBD ligation model is not similar to children with biliary atresia, both situations suggest the evidence of TGF- $\beta 1$ getting involved in the process of nephromegaly. Probably, HGF potently suppresses TGF- $\beta 1$ expression and thus TGF- $\beta 1$ decreases in a reciprocal manner to the increase in
HGF level during liver injury. This reciprocal change of HGF and TGF- $\beta 1$ manifesting as transiently or persistently elevated renal HGF/TGF- $\beta 1$ ratios may initiate the process of renal hypertrophy in CBD ligation rats or persistent nephromegaly in children with biliary atresia.

HGF is a potent renotropic factor that may be involved very early in postnephrectomy renal hypertrophy (5-7). However, no data have demonstrated evidence on the role of TGF- $\beta 1$ to potentiate the mitogenic signal of HGF in compensatory renal growth. As in renal hypertrophy in CBD ligation rats, we also found a transiently increased renal HGF/TGF- $\beta 1$ ratio before clinically evident compensatory renal growth after unilateral nephrectomy in young rats. This elevated renal HGF/TGF- $\beta 1$ up-regulated c-met protein in the kidney, suggesting HGF involvement in the process of compensatory renal growth. However, the contributing factor of elevated renal HGF/ TGF- $\beta 1$ ratio after uninephrectomy depends on a decrease of renal TGF- $\beta 1$ when compared with sham controls. Our results reveal suppressed TGF- $\beta 1$ mRNA expression in the remaining kidney during the same time frame and provide a reasonable explanation for the low renal TGF- $\beta 1$ level in postnephrectomy renal growth.

Compensatory renal growth after unilateral nephrectomy probably proceeds through a cascade of actions of growth factors in the kidney, such as HGF in the early phase (5-7), IGF-I in the midphase (25-27), and epidermal growth factor in the late phase (28). To our knowledge, HGF and its receptor c-met protein are undoubtedly initial mediators to start the specific renal growth (5-7). Our data indicate for the first time the interaction of growth factors in this cascaded pathway. The reciprocal relationship between HGF and TGF- $\beta 1$ is interesting. A decreased renal HGF/TGF- $\beta 1$ ratio is associated with chronic renal injury and renal fibrosis in mice (20-24), whereas a high renal HGF/TGF- $\beta 1$ ratio after uninephrectomy or in CBD ligation rats probably results in elevated renal mass.

In conclusion, a transiently elevated renal HGF/TGF- $\beta 1$ ratio is noted soon after uninephrectomy and later after CBD ligation, and may be associated with the subsequent renal hypertrophy. The exact stimulus for up-regulation of HGF and down-regulation of TGF- $\beta 1$ in these experiments remains unclear, however, the transient reciprocal change of HGF and TGF- $\beta 1$ manifesting as an increased renal HGF/TGF- $\beta 1$ ratio suggests the probable role of TGF- $\beta 1$ for renal growth control and may initiate a cascade of actions to proceed to renal hypertrophy in liver injury or unilateral nephrectomy.

\section{REFERENCES}

1. Boechat MI, Querfeld U, Dietrich RB, Cohen A, Kangarloo H, Vargas J 1986 Large echogenic kidneys in biliary atresia. Ann Radiol 29:660-662

2. Tsau YK, Chen CH, Chang MH, Teng RJ, Lu MY, Lee PI 1997 Nephromegaly and elevated hepatocyte growth factor in children with biliary atresia. Am J Kidney Dis 29:188-192

3. Aldana PR, Goerke ME, Carr SC, Tracy TF Jr 1994 The expression of regenerative growth factors in chronic liver injury and repair. J Surg Res 57:711-717

4. Kawaida K, Matsumoto K, Shimazu H, Nakamura T 1994 Hepatocyte growth factor prevents acute renal failure and accelerates renal regeneration in mice. Proc Nat Acad Sci U S A 91:4357-4361

5. Nagaike M, Hirao S, Tajima H, Noji S, Taniguchi S, Matsumoto K, Nakamura T 1991 Renotropic functions of hepatocyte growth factor in renal regeneration after unilateral nephrectomy. J Biol Chem 266:22781-22784 
6. Ishibashi K, Sasaki S, Sakamoto H, Hoshino Y, Nakamura T, Marumo F 1992 Expressions of receptor gene for hepatocyte growth factor in kidney after unilateral nephrectomy and renal injury. Biochem Biophys Res Commun 187:1454-1459

7. Joannidis M, Spokes K, Nakamura T, Faletto D, Cantley LG 1994 Regional expression of hepatocyte growth factor/c-met in experimental renal hypertrophy and hyperplasia. Am J Physiol 267:F231-F236

8. Michalopoulos GK, DeFrances MC 1997 Liver regeneration. Science 276:60-66

9. Tsau YK, Lu MY, Ni YH 2001 Nephromegaly and elevated plasma hepatocyte growth factor-transforming growth factor- $\beta 1$ ratio in infants with fulminant hepatitis or biliary atresia. Am J Kidney Dis 38:279-285

10. Tsau YK, Jou ST, Ni YH 2002 Nephromegaly relates to hepatocyte growth factor dysregulation in biliary atresia. Pediatr Nephrol 17:554-559

11. Symeonidis A, 1957 Morphologic and functional changes in the livers of rats after ligation or excision of the common bile duct. Am J Pathol 33:13-27

12. Chomczynski P 1993 A reagent for the single-step simultaneous isolation of RNA, DNA and proteins from cell and tissue samples. Biotechniques 15:532-537

13. Chen YM, Chien CT, Hu-Tsai MI, Wu KD, Tsai CC, Wu MS, Tsai TJ 1999 Pentoxifylline attenuates experimental mesangial proliferative glomerulonephritis. Kidney Int 56:932-943

14. Preisig P 1999 A cell cycle-dependent mechanism of renal tubule epithelial cell hypertrophy. Kidney Int 56:1193-1198

15. Kono S, Nagaike M, Matsumoto K, Nakamura T 1992 Marked induction of hepatocyte growth factor mRNA in intact kidney and spleen in response to injury of distant organs. Biochem Biophys Res Commun 186:991-998

16. Braun L, Mead JE, Panzica M, Mikumo R, Bell GI, Fausto N 1988 Transforming growth factor- $\beta$ mRNA increases during liver regeneration: a possible paracrine mechanism of growth regulation. Proc Natl Acad Sci U S A 85:1539-1543

17. Russell WE, Coffey Jr, RJ Ouellette AJ, Moses HL 1988 Type $\beta$ transforming growth factor reversibly inhibits the early proliferative response to partial hepatectomy in the rat. Proc Natl Acad Sci U S A 85:5126-5130

18. Santos OF, Nigam SK 1993 HGF-induced tubulogenesis and branching of epithelial cells is modulated by extracellular matrix and TGF- $\beta$. Dev Biol 160:293-302
19. Taipale J, Keski-Oja J 1996 Hepatocyte growth factor releases epithelial and endothelial cells from growth arrest induced by transforming growth factor- $\beta 1$. J Biol Chem 271:4342-4348

20. Mizuno S, Matsumoto K, Kurosawa T, Mizuno-Horikawa Y, Nakamura T 2000 Reciprocal balance of hepatocyte growth factor and transforming growth factor- $\beta 1$ in renal fibrosis in mice. Kidney Int 57:937-948

21. Matsumoto K, Mizuno S, Nakamura T 2000 Hepatocyte growth factor in renal regeneration, renal disease and potential therapeutics. Curr Opin Nephrol Hypertens 9:395-402

22. Mizuno S, Matsumoto K, Nakamura T 2001 Hepatocyte growth factor suppresses interstitial fibrosis in a mouse model of obstructive nephropathy. Kidney Int 59:1304-1314

23. Mizuno S, Nakamura T 2004 Suppressions of chronic glomerular injuries and TGF- $\beta 1$ production by HGF in attenuation of murine diabetic nephropathy. Am J Physiol Renal Physiol 286:F134-F143

24. Azuma H, Takahara S, Matsumoto K, Ichimaru N, Wang JD, Moriyama T, Waaga AM, Kitamura M, Otsuki Y, Okuyama A, Katsuoka Y, Chandraker A, Sayegh MH, Nakamura T 2001 Hepatocyte growth factor prevents the development of chronic allograft nephropathy in rats. J Am Soc Nephrol 12:1280-1292

25. Stiles AD, Sosenko IR, D'Ercole AJ, Smith BT 1985 Relation of kidney tissue somatomedin-C/insulin-like growth factor 1 to postnephrectomy renal growth in the rat. Endocrinology 117:2397-2401

26. Fagin JA, Melmed S 1987 Relative increase in insulin-like growth factor 1 messenger ribonucleic acid levels in compensatory renal hypertrophy. Endocrinology 120:718-724

27. Lajara R, Rotwein P, Bortz JD, Hansen VA, Sadow JL, Betts CR, Rogers SA Hammerman MR 1989 Dual regulation of insulin-like growth factor 1 expression during renal hypertrophy. Am J Physiol 257:F252-F261

28. Jennische E, Andersson G, Hansson HA 1987 Epidermal growth factor is expressed by cells in the distal tubules during postnephrectomy renal growth. Acta Physiol Scand 129:449-450 